\title{
PROCLAMATIE.
}

\section{DE GOUVERNEUR,}

\author{
Aan de Slavenbevolking in de Kolonie Suriname!
}

Het heeft Zijne Majesteit Onzen geeerbiedigden Koning behaagd den dag te bepalen, waarop de slavernij in de kolonie Suriname voor altijd afgeschaft zal zijn.

Op den 1n Julij 1863 zijt Gij vrij!

Maar de Koning, verlangende allen die onder Hoogstdeszelfs vaderlijk gezag leven gelukkig te zien, heeft gewild dat $\mathrm{U}$ die blijde tijding reeds nu bekend gemaakt zoude worden, opdat $\mathrm{Gij}$ in vreugde en tevredenheid dat zoo zeer gewenschte tijdstip afwachten kunt.

Van harte wensch ik U daarmede geluk, als ook mij zelven dat het $\mathrm{mij}$, als 's Konings vertegenwoordiger, gegeven is $\mathrm{U}$ die blijde mare aan te kondigen.

Ik durf er dan ook op rekenen dat Gij, door Uwen lust tot arbeid, door een onbesproken gedrag en door gehoorzaamheid aan Uwe meesters, bewijzen zult $\mathrm{U}$ de weldaad waardig te willen betoonen, die $\mathrm{U}$ tegen den In Julij 1863 verzekerd is.

Maar niet minder verwacht ik van $U$ dat $\mathrm{Gij}$, na den dag Uwer vrijwording, ordelijk en ondergeschikt aan het Bestuur, Uwe pligten als vrije menschen zult betrachten, geregeld werkende tegen een billijk loon, waarover Gij naar welgevallen zult kunnen beschikken tot verzorging van $\mathrm{U}$ zelven en de Uwen.

Dusdoende zult Gij het mij gemakkelijk maken, de wijze bedoelingen des Konings voor Uw toekomstig welzijn ten uitvoer te leggen.

En om $U$ des te beter in staat te stellen Uwe toekomstige regten en verpligtingen te leeren kennen, zal van deze Proclamatie en van de Wet ${ }^{1}$ ), voor zoo ver die U betreft, eene vertaling in het Neger-Engelsch worden gemaakt en bij deze gevoegd.

Paramaribo, den 3 October 1862.

VAN LANSBERGE.

Ter ordonnantie van den Gouverneur, De Hoofd-Commies, belast met de functiën van den Gouvernements-Secretaris,

J. E. WESENHAGEN.

Uit: Surinaamsche

Courant 3 Oct. 1862.

1) De wet van 8 Aug. 1862, S. 164, G.B. 1862 no. 6. De vertolkte artikelen zijn: $1,3,10$ en 18-36. (Red.) 
PR OCLAMATIE.

DE GOUVERNEUR,

Aan de vrygemaakte bevolking op Curaçao en onderhoorigheden.

Op den 30 September des vorigen jaars had alhier de afkondiging plaats der wet, waarby het Zyne Majesteit onzen geëerbiedigden Koning behaagde te bepalen, dat op den 1 July 1863 de slaverny op Curaçao en de onderhoorige eilanden voor altyd afgeschaft zal zyn.

Die blyde dag is heden aangebroken.

Van stonde aan zyt gy vrije menschen en treedt gy in de maatschappy als ingezetenen der kolonie.

Van harte wensch ik U geluk met de weldaad door de vaderlyke zorg des Konings U geschonken; opregt moogt gy U er in verheugen, maar gy moet $\mathrm{U}$ het voorregt ook waardig betoonen.

Hebt gy in uwen vorigen staat U steeds onderscheiden door een stil, rustig gedrag en gehoorzaamheid aan uwe voormalige meesters, thans, als vrije menschen, - ik durf er vast op vertrouwen, - zult gy steeds ordelyk en ondergeschikt aan het bestuur, uwe pligten als ingezetenen der kolonie betrachten, geregeld werkende tegen een billyk loon, waarover gy naar welgevallen kunt beschikken, tot verzorging van Uzelven en de uwen.

Het bestuur zal uwe belangen behartigen en die zooveel doenlyk trachten te bevorderen.

Hebt gy raad of voorlichting noodig, wendt $U$ tot den districtscommissaris in uw district of tot de andere bevoegde autoriteiten, die U behulpzaam zullen zyn in alles wat strekken kan ter bevordering van uw welzyn.

En zal van deze Proclamatie eene vertaling in de Landstaal gemaakt worden,

Uit: Publicatie-Blad 1863 No. 26.

Curaçao den 1 July 1863. J. D. CROL. 


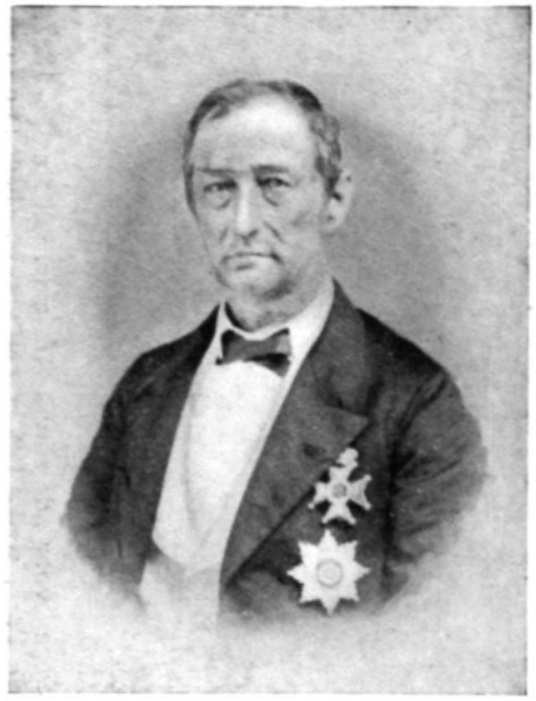

Johannis Didericus Crol (?1806-18 Aug. 1870), van 23 April 1859 tot 16 April 1866 gouverneur van Curaçao. - Naar een portret in het bezit van mr B. de Gaay Fortman.
Reinhart Frans Cornelis van Lansberge (6 Mrt 1804-13 Juni 1873), van 28 April 1859 tot 29 Juni 1867 gouverneur van Suriname. Naar een familieportret in het bezit van J. W. G. van Lansberge. Op zijn borst het Commandeurskruis van de Nederlandse Leeuw, dat hem naar aanleiding van de emancipatie werd verleend, en de Poolster van Zweden. 


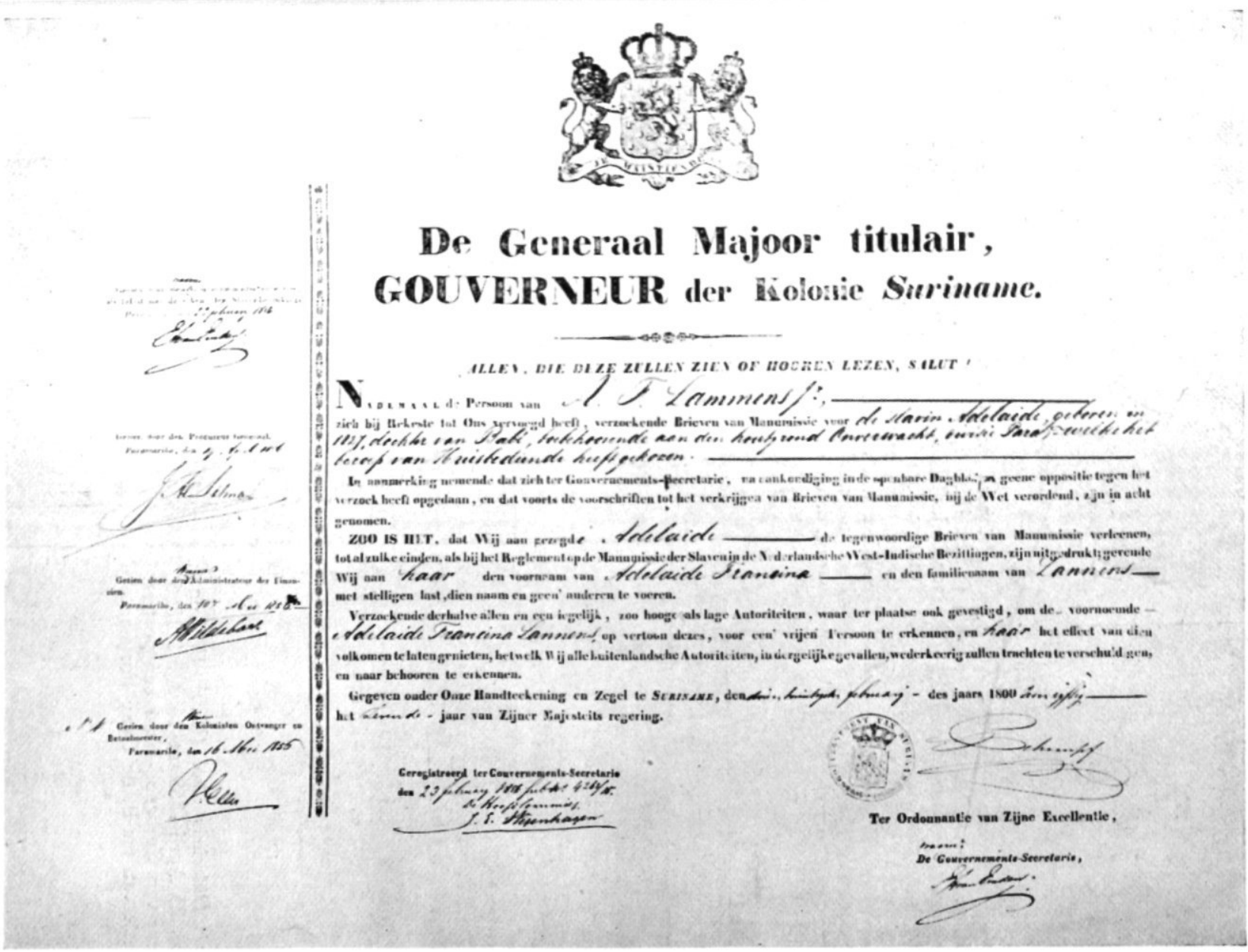

Brief van Manumissie, op verzoek van A. F. Lammens Jr. verkregen voor ,,de slavin Adelaide, geboren in 1827 , dochter van Babé, toebehorende aan den houtgrond Onverwacht, divisie Para, welke het beroep van Huisbediende heeft gekozen." Aan haar werd gegeven . den voornaam van Adelaid? "Francina en den familienaam van Lannens met stelligen zes en vijftig...." - Naar een brief aanwezig in het Algemeen Rijksarchief. 